\title{
Study and Analysis of life of Roller
}

\author{
Akshay Rewat Walde', Prof. S. M. Awatade ${ }^{2}$ \\ ${ }^{1} P G$ Student, ${ }^{2}$ Assistant Professor \\ Mechanical Engineering Department, Priyadarshini College of Engineering, Nagpur - India.
}

Received on: 20 June, 2021

Revised on: 22 July, 2021

Published on: 24 July, 2021

\begin{abstract}
A hard roller burnishing would be best suitable since the burnishing tool can be readily installed on the same CNC machine setting, Surface finish affects wear resistance, load bearing capacity, and corrosion resistance of the surface of the component. During burnishing process, the tool compresses the outer surface layer by the polished hardened tool (ball or roller) so that it reduces the surface roughness. Residual stress is that which remains in a body that is stationary and at equilibrium with its surroundings. On the other hand, compressive stresses sometimes introduced deliberately, as in shot peening, burnishing, which is used to improve fatigue resistance. Those rollers fail by fatigue. So, this research built a numerical simulation model to find the optimum size of those rollers which give the least contact stresses and so the longest fatigue life. Then those rollers were replaced by hollow ones. The numerical simulation results showed that the contact stresses values decreased in case of having the rollers hollow, which means longer fatigue lives of those rollers. The hollow rollers were found to live more than 30 times the solid ones under same loading conditions. To validate the simulation results and practical application of the proposed model by Flugrad and Qamhiyah, two traction drives were manufactured from aluminum with the optimum dimensions found numerically. The hollow rollers were manufactured with $60 \%$ percentage of hollowness, that the ratio of the internal diameter to the external diameter was $60 \%$. The hollowness was filled with rubber which has very low modulus of elasticity, which is very close to represent the hollow space. The two
\end{abstract}

friction drive models were experimentally tested and could successfully transmit motion and reduce speed.

Keywords- Burnishing process, peening, won misses stresses, fatigue life prediction of roller bearings, hollow and solid rollers

\section{I- INTRODUCTION}

S urface parameters (roughness, hardness, residual stress) are crucial factors to decide fatigue life of materials. Poor surface finish lead moisture content on surface region of material and import tensile residual stress. These two factors are very harmful for fatigue behavior of materials. Generally material removal process such as machining, grinding, etc. lead poor surface finish. After that, the material goes under super finishing process. Nowadays burnishing process becomes more popular as a finishing process.Surface finish affects wear resistance, load bearing capacity, and corrosion resistance of the surface of the component. During burnishing process, the tool compresses the outer surface layer by the polished hardened tool (ball or roller) so that it reduces the surface roughness. Other parameter like surface hardness is inversely proportional to the surface hardness. The reduction in surface roughness increases the surface hardness simultaneously. 


\section{International Journal of Innovations in Engineering and Science, www.ijies.net}

Residual stress is that which remains in a body that is stationary and at equilibrium with its surroundings. It can be very detrimental to the performance of a material or the life of a component. Alternatively, beneficial residual stresses introduced deliberately. Residual stresses are more difficult to predict than the in-service stresses on which they superimpose. For this reason, it is important to have reliable methods for the measurement of these stresses and to understand the level of information about this stress.

\section{II- $\quad$ ANALYSIS}

One of the best advanced finite element software packages of those extensively used for structure analysis of contact problems and dynamic analysis is ABAQUS.

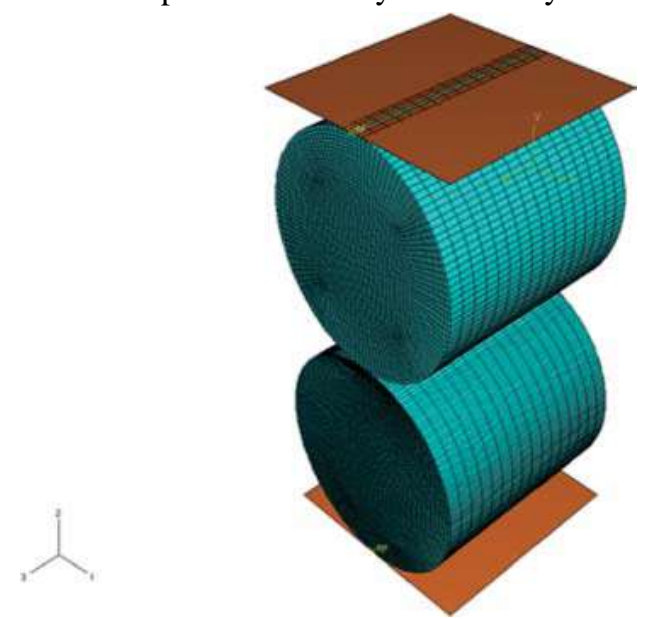

Fig 1- Two identically sized rollers in contact

Using ABAQUS, two cylindrical rollers in contact were modeled. Those rollers were subjected to a combined loading of normal and tangential components. They were subjected to normal loading through two analytically rigid zero thickness sheet plates, as shown in Figure 1, in which two solid identically sized rollers are in contact (Model 1). The load was applied through those rigid bodies to ensure uniform distribution of loading on the roller surface and chosen to be analytically rigid so that they do not affect the results in the contact region between the two rollers. A tangential loading component was also applied to the two cylindrical rollers. The value of that tangential loading was one-third of the normal loading. A sufficient coefficient of friction of 0.35 was assumed between the two rollers' surfaces to be more than one-third so that no slipping may occur. Analytically rigid bodies have been used to be able to run the analysis on ABAQUS. The stresses that have been used in the fatigue life analysis are the ones in the contact cylinders' halves, away from the rigid body effect. Two main models have been built. The first model, Model 1, was with rollers of the same size. The other model was with two rollers of different size such that one of the cylinders is twice as large as the other. This model is called Model 2. The analysis was started with both rollers solid. The results of both models have been verified by the solution of Smith and Liu4 in the case of parallel rollers in combined rolling and sliding. This is a good check of the validity of the models and the boundary conditions applied on the model. After the validity of the ABAQUS results was checked, the two solid rollers were replaced by hollow rollers. The case of having one hollow roller with one solid roller has also been studied. Different hollowness percentages have been tested: 20, 40, 60 and $80 \%$. The same procedure was applied to Models 1 and 2.

ABAQUS enabled us to describe all the stress components' values and distributions through the rollers' bodies. Highly stressed regions with Von Mises stresses have been determined. Those regions with stresses higher than the endurance limit of the material used for the two rollers are referred to as risk volumes. The endurance limit or the fatigue life of the material was defined by Shingly and Mischke25 as the strength beyond which failure will not occur no matter how great the number of cycles. Both rollers are assumed to be made of CVD 52100 steel, with an endurance limit of $680 \mathrm{MPa} .26$ For the identically sized model (Model 1), the outer diameter and the length of the roller were both $20 \mathrm{~mm}$. In the non-identically sized rollers (Model 2), the diameter of the secondary roller is doubled with the same length of $20 \mathrm{~mm}$. The secondary roller is the roller that was kept solid in the second stage while the main roller is the one that was hollow in that stage. The behavior of the main roller has been investigated when it is in contact with another identically sized roller, as is the case in Model 1, and when it is in contact with the inner race or the outer race, as is the case in the nonidentically sized rollers model (Model 2). A consistent convention is used for naming the models based on whether the rollers are of the same size or not, the percentage of hollowness, and whether one roller is hollow or both rollers are hollow.

The name of each model starts with $\mathrm{M}$, which refers to Model. As mentioned earlier, identically sized models are called Model 1, while non-identically sized roller models are called Model 2. Figure 2 shows a model of two identically sized rollers, with $60 \%$ of hollowness. Thus, it is called M 1-60. Then the name is followed by the word (One) or (Two) to refer to the number of hollow rollers in the model. In the case of a solid model, there is no need to use any of these two words. The letter 


\section{International Journal of Innovations in Engineering and Science, www.ijies.net}

$\mathrm{T}$ was added to the name of the models to indicate that those models are subjected to a combined normal and tangential loading.

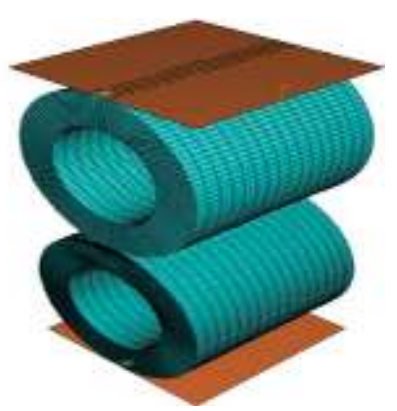

Fig 2- Two identically sized hollow rollers in contact

\section{III- FUTURE SCOPE}

Machining is the process of material removal in order to get the component into desired shape and size. The properties of machined components have gained a large importance. The properties such as surface finish, surface hardness, wear resistance, corrosion resistance, etc are to be considered. The surface finishing operations such as honing, lapping, grinding, etc can be replaced by burnishing process as the other processes exert tensile force on the component which reduces life of component due to fatigue, tension, etc. Thus, compressive stresses are found beneficial over tensile stresses on component surface.

Table 1- Fatigue life estimation of Model using IH theory

\begin{tabular}{|l|c|}
\hline \multicolumn{1}{|c|}{ Model 2 } & Relative fatigue life \\
\hline M 2-20 One & 5.2 \\
\hline M 2-20 Two & 18 \\
\hline M 2-40 One & 15 \\
\hline M 2-40 Two & 47.6 \\
\hline M 2-60 One & 85.5 \\
\hline M 2-60 Two & 87.5 \\
\hline M 2-80 One & 7.4 \\
\hline M 2-80 Two & 0.5 \\
\hline
\end{tabular}

Compressive stresses can also be produced by processes other than burnishing which are shot peening, laser shock peening, etc. But these stresses were found to be relaxed when exposed to heat. This thermal relaxation of compressive stresses shortens the component life and reduces its performance. So burnishing came up as a process that could impart compressive stresses that remain unaffected also in thermal variations.
- The study on effect of process parameters like speed, feed, etc on power consumption.

- Analysis of physical and mechanical properties developed during and after burnishing can be studied by upgrading the FEA model using software like ANSYS to consider the changes.

- Study the effect on surface hardness by change in process parameters.

- Study the effect on surface roughness by change in process parameters.

\section{IV- CONCLUSION}

When comparing the response of the hollow rollers in contact, with an identically sized roller, with a hollow roller in contact, with a roller of twice size, we can see many differences in their response to a combination of normal and tangential loading. Under the same loading, rollers in Model 2 have longer fatigue lives than rollers in Model 1. That can clearly be seen when comparing corresponding values in Table 1. This result applies for all hollowness percentages except when both rollers have $80 \%$ hollowness. That might be related to increasing the flexibility and increasing the contact area and so decreasing the contact stresses of a roller in contact with a bigger sized roller. Increasing the contact width decreases the contact stress but has nothing to do with the shearing stress. The Von Mises stress contains all the stress components. Thus, decreasing the contact stress will decrease one of the components and decreases the Von Mises stress value. On the other hand, when the hollowness exceeds $60 \%$, from the sides and the inner surfaces tend to increase the shearing stresses in the contact region and the risk volume, resulting in greater Von Mises stress values and decreased fatigue life.

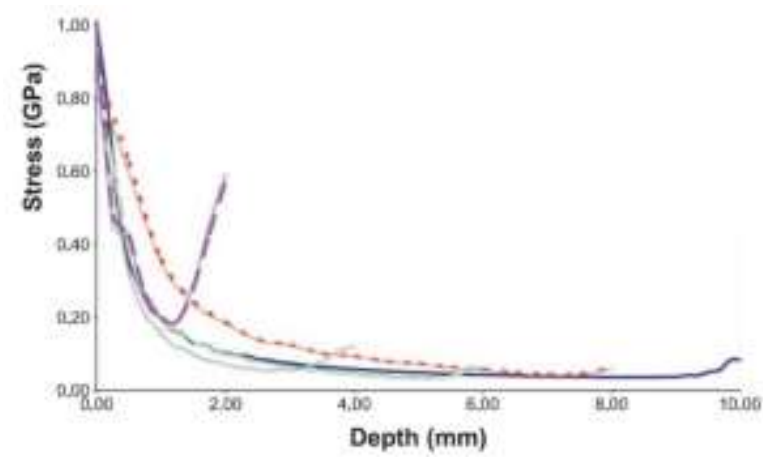

Fig 3. (a) -Non-identically sized roller models under combined loading, 


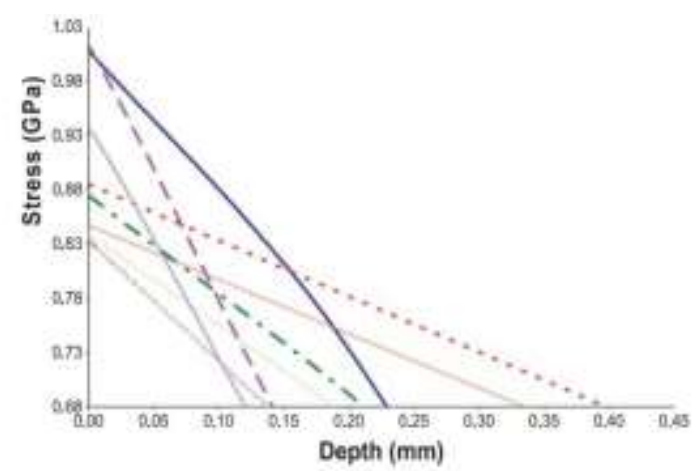

Fig 3-(b) non-identically sized roller models under combined loading

\section{REFERENCES}

[1] Gohar, R., "Elastohydrodynamics," Imperial College Press,2001 Ai, X., "Development of Zero-Spin Planetary Traction Drive Transmission: Part 1-Design and principles of Performance calculation," Journal of Tribology Trans.ASME, Vol. 124, 2002, pp. 386-391.

[2] Ai, X., "Development of Zero-Spin Planetary Traction Drive Transmission: Part 1-002, pp. 392397.Performance Testing and Evaluation," Journal of Tribology Trans. ASME, Vol. 124,

[3] Flugrad, D., and Qamhiyah, A., "A Self-Actuating Traction-Drive Speed Reducer, "Journal of Mechanical Design, Vol. 127, No. 4, July 2005, pp. 631636.

[4] Hertz, H., "Gesammelte Werke," Leipzig, Germany, Vol. I, 1895; English translation in Miscellaneous Papers, 1896.

[5] Lundberg, G., "Elastische Beruehrung Zweier Halbraeume," Forschung Auf Dem Gebute Des Ingwieurw 